\title{
Ethnicity and covid-19: analysis must be inclusive and transparent
}

\section{Padmasayee Papineni consultant in infectious diseases ${ }^{1}$, Tiffanie Harrison clinical nurse specialist ${ }^{1}$, Juliette Mutuyimana infection consultant ${ }^{2}$}

${ }^{1}$ Ealing Hospital, London North West University Healthcare NHS Trust, Southall UB1 3HW, UK; ${ }^{2}$ Kingston Hospital NHS Trust, Kingston upon Thames, UK

Khunti and colleagues discuss the possible association between ethnicity and severity of covid-19. ${ }^{1}$ Our experience in London would suggest such a link, and further analysis of clinical outcomes data should be a priority.

Ethnicity is multidimensional. ${ }^{2}$ Analysis of the UK covid-19 data needs to take into consideration that those of black, Asian, and minority ethnic (BAME) background have vastly heterogenous cultures, behaviours, family and community dynamics, religions, and languages. Defining (even through self-identification) patients as "black" or "Indian" hides the diversity within these ethnic groups, and further subgroup analysis is required to understand the complex social and economic factors at play.

In celebrations of the NHS during the pandemic, the faces of BAME NHS staff have been missing from front page coverage in the national press, ${ }^{3}$ despite making up over $20 \%$ of the workforce. ${ }^{4}$ Women have been excluded from the national and global discourse on covid- 19,5 and black women are noticeably absent. Any analysis of ethnicity and covid-19 must involve accurate representation from communities affected for true credibility.
Rather than being a "great equaliser," covid-19 is emphasising the entrenched inequality that exists in UK society. As medical professionals, it is our duty to lend our voices to the calls for prompt and transparent analysis of the data.

Competing interests: No competing interests.

Khunti K, Singh AK, Pareek M, Hanif W. Is ethnicity linked to incidence or outcomes of covid-19?BMJ 2020;369:m1548. 10.1136/bmj.m1548 32312785

2 Agyemang C, Bhopal R, Bruijnzeels M. Negro, black, black African, African Caribbean, African American or what? Labelling African origin populations in the health arena in the 21st century. J Epidemiol Community Health 2005;59:1014-8.

10.1136/jech.2005.035964 16286485

3 Stephenson J. Exclusive: Are we whitewashing coronavirus? Nursing Times 2020 Ap 12. https://www.nursingtimes.net/news/coronavirus/exclusive-are-we-whitewashingcoronavirus-12-04-2020/

4 Gov.uk. NHS workforce. 6 January 2020. https://www.ethnicity-facts-figures.service.gov. uk/workforce-and-business/workforce-diversity/nhs-workforce/latest

5 Wenham C, Smith J, Morgan RGender and covid-19 Working Group. Covid-19: the gendered impacts of the outbreak. Lancet 2020;395:846-8. 10.1016/S0140-6736(20)30526-2 32151325

Published by the BMJ Publishing Group Limited. For permission to use (where not already granted under a licence) please go to http://group.bmj.com/group/rights-licensing/ permissions 